\title{
Organizational Culture Predicts Emotional Intelligence among Pharmaceutical Industrial Employees
}

\author{
ANDLEEB AKHTAR \\ Lecturer, Department of Psychology, The University of Haripur, Haripur, Pakistan \\ PhD Scholar, Psychology Department, FURC, Foundation University Islamabad, Pakistan \\ Email: andleebmalik81@yahoo.com \\ Dr. SADAF AHSAN \\ Assistant Professor, Psychology Department, FURC, Foundation University Islamabad, Pakistan \\ Email: sdfmuneer@yahoo.com
}

RAHAT BAKHTIYAR

Lecturer, Psychology Department, FURC, Foundation University Islamabad, Pakistan

Email: rahat.psy@gmail.com

\begin{abstract}
Today organizations are faced with challenges regarding management of employees that need to be dealt technically. The organizational culture thus facilitates organizations in creating a medium for productive behaviors. The study was intended to reveal the relationship between Organizational Culture (OC) and Emotional Intelligence (EI) on a sample of 100 employees from pharmaceutical sector of Hattar Industrial state, Pakistan. The study was conducted using Denison Organizational Culture Survey and Genos Emotional Intelligence Scale. The alpha reliabilities were found out to be .94 and .86 of both scales respectively. SPSS was used for data analysis. The hypotheses of study were supported. It was found that organizational culture predicts emotional intelligence positively and significantly with ( $\beta=.801, R 2=.638$ ) and $p<.001$. There exists a high significant positive correlation between the two variables. Results indicated significant gender differences and significant differences of management levels also. Among the demographic variables (age, gender, salary, education, total job experience) only gender has a significant impact on organizational culture and emotional intelligence.
\end{abstract}

Keywords: Denison Organizational Culture Survey, Emotional Intelligence, Hattar Industrial State, Pharmaceutical Sector, Genos.

\section{Introduction}

Nowadays organizations are thriving for swift growth, continuous perfection, profitable business, future preparedness and excellence of their activities in worldwide (Salajegheh, Chamanifard, Chamanifard, \& Nikpour, 2015). Work environment is dynamic, continuously under unpredictable changes. For an understanding of organizational behavior, organizational culture has a very imperative role. For the last 3 decades organizational culture is proving as an important contributor towards organizational behavior. Due to its covert nature, it has a crucial role in influencing the employees and management activities (Azhar, 2003). Employees face reorganizations, budget cuts and job alteration and experience unrestrained change. They experience distress, apprehension, or worry. Unmanaged emotions are often transmittable to others and affect change process and individual adversely. Consequently, training need of emotional intelligence for employees seems important (Hendrix, 2013). Therefore, organizations pay out more for time, money and efforts to achieve high performance. In this era of change, attaining performance eminence through 
conventional management methods is not on the cards and thus, organizations need to execute new managerial approaches (Taslimi, 2015). Hence, employees do not behave in a value-free system. It's the organization culture that direct, tempers and govern the behavior of managers and employees (Brown \& Starkey, 2000). Rapid organizational changes engage and stimulate among employees, intense emotions as a consequence to perceived losses and inconsistent values. Employees experience emotions that may include apathy, anxiety, cynicism, and optimism due to low level of emotional intelligence (Hendrix 2013). Organizational culture acts as a medium where behaviors can be embedded towards excellence. Several studies have revealed the factors highlighting that organizational culture is an effective agent for performance of organizational (Irefin \& Mechanic, 2014; Denison \& Mishra, 1995). Emotional Intelligence (EI) enhances working capacity of employees, and it also assists employees in stress management. Organizational culture strongly influences employees' behaviors and attitudes (Wagner, 1995). Organizational culture gives norms and standards that prescribe the essential behaviors of employees in any given organization (Manetje, \& Martins, 2009). Very few researches have studied the impact of organizational culture over emotional intelligence (Ghenu \& Tudor, 2016; Ugoani, 2015; Lee \& Yazdanifard, 2013). A large number of research studies found the impact of emotional intelligence on leadership (Ilyas \& Abdullah, 2016; Riggio \& Reichard, 2008; Fambrough et al., 2008). Little is known about the emotional intelligence of industrial employees, thereby showing a gap in research in this area. Recent researches are focusing on an emotionally intelligent organizational culture (Ghenu \& Tudor, 2016; Ugoani, 2015; Rude, 2014; Downey, Roberts, \& Stough, 2011). Organizational culture acts as contextual variable where the behaviors, values, attitude, feelings and emotions of the employees can be aligned according to need of the time and goals of organizations, allowing certain types of behaviors and emotions to be accepted towards future endeavors. Current study, therefore, hypothesizes the relationship between organizational culture and emotional intelligence. Several researches have proven that these two variables impact organizational processes and outcomes influencing organizational performance positively. The research question that arises here is about nature of relationship between the two variables.

Organizational culture is a sense of communal basic assumptions, learned to resolve the intricacies and dilemmas of external adaptation and internal integration (Schein, 1985). Brown (1998) introduces organizational culture as the configuration of beliefs, values, and attitudes during the course of organization's history, and demonstrated its significance in organizational activities and behaviors. Denison, (2000) proposed four traits of organizational culture. i) Involvement is the degree of influence of employees over organizational decisions and their connectedness to organizational goals. ii) Consistency is the degree of understanding of the shared-belief systems in their organization and the ability to behave accordingly in a predictable manner during ambiguous situations. iii) Adaptability is the degree of organizational responding to both internal external customers and environment, supporting organizational learning. iv) Mission is the degree of employees' knowledge and sharing of purpose, objectives and vision of organization (Dawson, 2010). Organizational culture is prime competitive advantage of high performance organizations (Kotter \& Heskett, 2011; Nganga and Nyongesa, 2012; Ahmed \& Shafiq, 2014) and it is closely related to productivity (Dwirantwi, 2012; Dugguh \& Dennis, 2014) employee performance and job-related activities (Awadh \& Saad, 2013) work effort and commitment (Manetje, \& Martins, 2009).

Emotional intelligence (EI) in general is defined as the capability to recognize emotions of oneself and others and controlled proper reaction to these emotions. EI is the self-management, social and selfawareness skill that boost the likelihood to attain goals of organization (Kerr, Garvin, Heaton \& Boyle, 2006) and assists in successful leadership (Fambrough et al. 2008). Mayer, Salovey and Caruso (2008) confirmed that EI basically is the ability to differentiate and regularize emotions of oneself and others. Emotionally intelligent leadership assists in organizational modifications in their respective organizations (Riggio \& Reichard, 2008). Daniel Goleman in 1996 used the term "emotional intelligence" in his book that became popular. There exist different opinions among scholars on definition and operation of emotional intelligence. Trait, ability, and mix model are three main models of EI as described by different scholars. Every model measures emotional intelligence from a diverse method and every model reinforces all other models. These models have no conflict with each other (Mayer \& Salovey, 2007). Most scholars 
concur that skills of emotional intelligence can be acquired, cultivated and learned through training and tutoring (Browning, Torain \& Patterson, 2011). Professionals of health sector do need higher level of EI as they deal with many patients daily and receive heavy workload. EI helps to generate healthier and better relations between colleagues, team members and staff in health sector (Jones,2007). Piper (2008) reported that health sector leaders need both skills: technical skills and EI skills to manage the latest complex provision system of healthcare. Palmer et al. (2004) mentioned the requirement of enhanced emotional intelligence of health sector leaders for ensuring good clinical efficiency (Suliman \& Al-Shaikh, 2007).

Emotional intelligence beyond conventional academic intelligence can also be defined as cluster of cognitive abilities (Zeidner et al., 2004). Definitions of EI can be categorized into either an ability model or mixed model by researchers. According to ability model of Mandell and Phewanti (2003) EI is defined as a cluster of abilities involving abstract perceiving and reasoning with information that comes from feelings. Mayer and Salovey (1997) have corroborated this model of EI as ability to perceive, appraise, and express emotion; the ability of accessing and/or generating feelings that facilitate thoughts; ability of understanding emotion and emotional knowledge; and ability of regulating emotions for promoting intellectual and emotional growth. Mayer, Salovey, and Caruso (2004) defined EI as capacity of reasoning about emotions for enhanced thinking in addition to taking it as the ability. Whereas Goleman (1995) and Bar-On (1996) were originators of mixed-model. After conducting their studies they established this approach. Goleman (1995) then defined EI as ability that recognizes and regulates emotions within self and within others. He also defined EI as arrangement of non-cognitive capabilities, competencies, and skills influencing the ability for successful coping of environmental demands and pressures (Bar-On, 2004). In short, mixedmodel has been linked to one s' ability as it interacts with the social behaviors, attributes and characteristics.

The Genos EI model (Gignac, 2010) takes in psychological attributes of direct relevance that identify, utilize and/or manage emotions and manifestation of EI skills across 7 individual dimensions: i) Emotional Self-Awareness (ESA) is the frequency of awareness of an individual about the emotions that can motivate thoughts and behaviours at work. It includes a balance of both positive-negative affect states. ii) Emotional Expression (EE) is frequency of expressing one's emotions in right time, right way and to right people. It includes items relevant to negative-positive emotions. iii) Emotional Awareness of Others (EAO) is frequency of identifying others' expressed emotions in the workplace and comprehension of emotions' nature affecting the workplace behaviors. iv) Emotional Reasoning (ER) is the frequency of some consideration of ones' own emotions and others' emotions in decision making at work. v) Emotional SelfManagement (ESM) is the frequency of emotions management in workplace successfully for maintaining a positive emotional state at work. vi) Emotional Management of Others (EMO) is relative frequency of emotions management of others at work successfully, motivating others for creating a positive work environment. vii) Emotional Self-Control (ESC) is the relative frequency of controlling own emotions properly at work or to concentrate the tasks in face of adverse emotion. It's the behavioral demonstration to control intense reactive emotions at work. Genos Total EI represents the frequency of all these emotionally intelligent behaviors.

EI impact positively on various job related outcomes e.g. working capability, employees job performance, job satisfaction and organizational efficiency and productivity (Semadar, Robins \& Ferris, 2006; Suliman \& Al-Shaikh, 2007; Afolabi, Awosola, \& Omole, 2010; Aboyade, 2013) leadership efficiency/ effectiveness (Kerr, Garvin, Heaton \& Boyle, 2006). Sy, Tram and O'Hara (2006) explained that higher level of employees' EI helps to overcome job stresses in better way producing improved outcomes than having less EI. Guleryuz et al. (2008) indicated a significant positive relationship between EI and job satisfaction and organizational commitment. The dimensions of EI were significant indicators for job satisfaction. Recent studies have focused the impact of EI in academic sector. Ranasinghe et al, (2017) studied EI in predicting academic performance of final year medical students alongwith self satisfaction and self-perceived stress. The results indicated that higher level of EI predicts better academic performance and strongly correlated with self satisfaction and lower self-perceived stress. EI was viewed as a better 
future coping strategy of stress in professional life. Extremera et al (2018) have found the relationship between adolescence cyberbullying victims with EI, suicidal ideation and self-esteem. The higher level of EI is correlated with low level of suicidal ideation and high level of self-esteem. Hence it is concluded that EI abilities have positive impact on mental health of individuals as well as organizations.

\section{Literature Review}

Organizational culture is a commonly shared sense of purpose due to a bond between organization and employee. Today it privileges individuals and their characteristics of subjectivity, absurdity and emotionality (Tolmats \& Reino, 2006). Therefore EI facilitate organization to materialize organizational culture and all level organizational actions (Langhorn, 2004). EI is imperative in workplace and plays a significant role for enhanced performance of education sector in Pakistan (Matthews, Zeidner, \& Roberts, 2004). Shahzad, Luqman, Khan, and Shabbir (2012) and Shahzad et al. (2013) established that a strong organizational culture impacts employee performance, goal achievement and organizational performance. As the emotionally intelligent individual in any organization, the goal achievement is rather easier. That's why most jobs, require some level of EI. Danaeefard et al., (2012) stated that EI contributes the avenue for growth of organizational culture in any organization. Moghadam, Jorfi and Jorfi (2010) highlighted that the organizations need to get along with change effectively. EI is a useful tool for dealing effectively with organizational change. Aboyade (2013) noted that if EI is lacking in university library workers and librarians face difficulties in dealing with their workforce in friendly environment. This may result in lack of working relationships, thereby ending in bitterness and acrimony. Haghighy, Shahrakimojahed \& Vahed, (2016) reported the relationship of organizational commitment, organizational culture and EI among managers and workers. The results showed a significant positive correlation between organizational culture, EI and organizational commitment, and positive non-significant relationship between organizational culture and EI, and predicting 48 percent variance in organizational commitment. Ghenu (2017) analyzed past literature regarding the relationship between leadership, emotional intelligence and organizational culture. She deduced from her analysis that transformational leadership is positively correlated with emotional intelligence. Solely and combined, these two variables impact organizational culture strongly. As a result of the combined impact of transformational leadership and higher EI, the leader becomes more effective through culture of organization.

Rude (2014) proposed that EI and organizational culture relationship is of reciprocal nature. Culture has huge impact over emotional process: organizational culture manipulates the choice of an action or behavior as a response to the event (Rude, 2014). Organizational culture thus acts as a medium where behaviors and emotions can be managed more properly. It acts as tool to modify and align the required emotions, behaviors, norms and attitudes. In this respect organizational culture acts as a predictor of workplace emotional intelligence. This has been focused in the current study.

\section{Research Paper Highlights}

- Sample is from Hattar Industrial State, Pakistan

- Sample includes industrial employees (rarely researched)

- Study of EI of Industrial Employees

- Study of relationship between organizational culture and EI

- Using refined research models: Denison Organizational Culture Survey \& Genos EI model

- Organizational culture predicts EI among industrial employees significantly

- Among demographic characteristics, impact of Gender is significant. 


\section{Theoretical Framework}

The cross-sectional survey research design and purposive sampling was used.

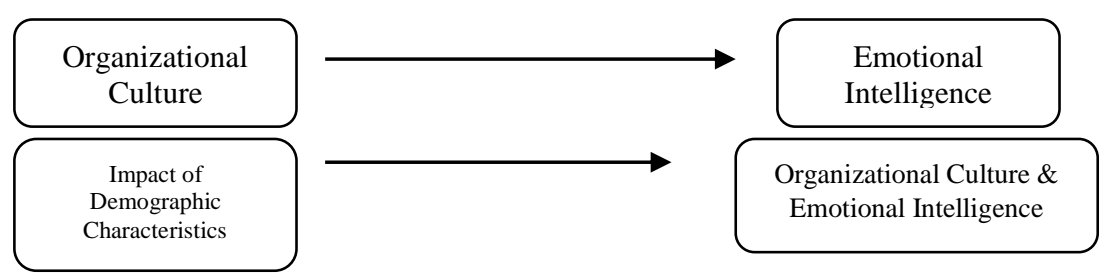

\section{Research Objectives}

The main objectives of this research were to study the relationship between organizational culture and EI among industrial employees of Hattar Industrial State, Haripur, Pakistan and the impact of demographic characteristics on variables. For this purpose the hypotheses are as follows:

H1: There will be a positive relationship between organizational culture and EI and among their subdimensions/subscales.

H2: Organizational culture will positively predict emotional intelligence.

H3: Traits of organizational culture ie Involvement, Consistency, Adaptability and Mission will predict EI positively.

\section{Population and Sample}

The sample consisted of 100 participants from pharmaceutical organizations in Hattar Industrial State, Haripur, Pakistan. Purposive sampling technique was used as the researcher desired to study some characteristics of rarely studied work environment ie industrial employees. The accessible population of interest were the industrial employees working in factories/manufacturing site. This work environment is different because the factories of industries usually hold different layers of management there and are situated away from the urban areas with special provision of certain resources. The demographic characteristics of sample included, job experience, age, management levels, gender, education. Job experience of employees ranged from 2 to 20 years. The age of the subjects ranged from 25 years to 65 years. The permission for data collection was obtained from the officials of the organizations/industries at Hattar. The participants were put up with request for filling in questionnaire. The questionnaires were administered individually. Confidentiality was assured, but the response rate was very low. The organizations included Qarshi, Pak Rison, Genome Pharmaceutical and WNS Field Pharmaceutical.

\section{Data Collection Method}

Survey research design was used to obtain data using questionnaires. Denison Organizational Culture Survey (DOCS) measured organizational culture. The organization scoring high on the cultural traits: involvement, consistency, mission and adaptability, has culture with high organizational effectiveness (Denison, 2000). Daniel Denison and William S. Neale (2000) developed DOCS. It has 4 culture traits affecting performance: Involvement, Consistency, Adaptability and Mission. The established reliability of the scale is .91. (Denison 2000). The items are assessed on Likert scale ranging from 1 (strongly disagree) to 5 (strongly agree). Each of these traits has three indexes (management practices). Each index has 5 items. Thus, there are 15 items under one trait and DOCS has 60 items for measuring traits of organization culture. Therefore, the minimum score on this scale is 60 and the maximum score is 300 . The items 15,24 , $29,34,39,43,50$, and 58 are the reverse items and are scored reversely. The determined alpha reliability is 
94. The subscale reliabilities have proven enough satisfactory. EI is the ability to recognize and deal with emotional cues and information. Genos inventory was used to measure the emotional intelligence. Individuals scoring high will have high emotional intelligence (Genos, 2018). The Genos EI Inventory (Concise) developed by Gignac (2010), was used to measure emotional intelligence at work. It's the concise form of the scale (short form). It comprises 31 statements with five responses 1 for Almost Never, 2 for Seldom, 3 for Sometimes, 4 for Usually, 5 for Almost Always. There are 7 sub dimensions of Genos EI Inventory: Emotional Self-Awareness (ESA), Emotional Expression (EE), Emotional Awareness of Others (EAO), Emotional Reasoning (ER), Emotional Self-Management (ESM), Emotional Management of Others (EMO) and Emotional Self-Control (ESC). The ESA has items: 2, 4, 24, 28 and EE has items: 5, 7, 9, 18, 29. Similarly EAO has items: 11, 12, 19, 22 and ER has items: 1, 8, 15, 16 17. The subscales of ESM has items : 3, 6, 13, 20, 21 and EMO has items: 14, 25, 27, 31. The ESC has items: 10, 23, $26,30$. Total EI score is obtained: ESA+EE+EAO+ER+ESM+EMO+ESC. The items 2, 4, 5, 6, 10, 11, 13, 22, 23, $27,29,31$ are the reverse scoring statements.

\section{Findings \& Evaluations}

Table 1: Demographic Characteristics of the Participants

\begin{tabular}{|c|c|c|c|}
\hline Demographic & Groups & f & $\%$ \\
\hline Gender & Male & 87 & 87.0 \\
\hline & Female & 13 & 13.0 \\
\hline Age & 20 - 30 years & 51 & 51.0 \\
\hline & $31-45$ years & 45 & 45.0 \\
\hline & 46 - 65 years and above & 4 & 4.0 \\
\hline Education & Matric/High School & 24 & 24.0 \\
\hline Level & Intermediate & 27 & 27.0 \\
\hline & Graduation & 28 & 28.0 \\
\hline & Post Graduation & 12 & 12.0 \\
\hline Average & Less than 20000 PKR & 42 & 42.0 \\
\hline Salary & 21000 to $50000 \mathrm{PKR}$ & 42 & 42.0 \\
\hline & 51000 to $100000 \mathrm{PKR}$ & 14 & 14.0 \\
\hline & More than $100000 \mathrm{PKR}$ & 2 & 2.0 \\
\hline Management & Lower Management & 42 & 42.0 \\
\hline Level & Middle Management & 39 & 39.0 \\
\hline & Senior Management & 11 & 11.0 \\
\hline & Other & 8 & 8.0 \\
\hline Organizations & Pak Rison & 48 & 48.0 \\
\hline & Qarshi & 43 & 43.0 \\
\hline & Genome Pharmaceutical & 5 & 5.0 \\
\hline & WNS Field Pharmaceutical & 4 & 4.0 \\
\hline
\end{tabular}

When the gender distribution of the participants in Table 1 is analyzed, the participants were $87 \%$ male $(87$ persons) and $13 \%$ women (13 persons). When the age levels of the participants was considered 20-30 age group was $51 \%$ (51 people), 31-45 age group was $45 \%$ (45 people), $46-65$ and above age group was $4 \%$ (4 people). According to the educational level of the participants, $24 \%$ (24 people) consisted of matric/ high school participants, intermediate level participants consisted of 27\% (27 people), $28 \%$ (28 people) consisted of graduation level participants, $28 \%$ (28 people) consisted of post graduation level participants, while diploma level participants consisted of $9 \%$ ( 9 people). Looking at the salary level of participants, people constituted less than 20000/- PKR salary were 42\% (42 people), people constituting 21000-50000/PKR salary were $42 \%$ (42 people), people constituting 51000-100000/- PKR salary were 14\% (14 people), 
where as people constituting more than 100000 PKR were salary $2 \%$ ( 2 people) . When the management levels of the participants was analyzed, lower management consisted of $42 \%$ (42 people), middle management consisted of 39\% (39 people), senior management consisted of 11\% (11 people), and 'other' included internees/daily wage employees that were $8 \%$ ( 8 people). The organizations from where the data was collected included four organizations: Qarshi, Pak Rison, Genome Pharmaceuticals and WNS Field Pharmaceuticals. Participants from Qarshi included 43\% (43 people), participants from Pak Rison were $48 \%$ (48 people), participants from Genome Pharmaceuticals were 5\% (5 people) and participants from WNS Field Pharmaceuticals were 4\% (4 people).

Alpha reliability coefficients, Pearson correlation and descriptive statistics, for study variables were calculated to test the hypothesis. Table 2 shows the Pearson correlation determined for the organizational culture and EI using DOCS and Genos EI Inventory (Concise) Scale. The correlation value for the studied variables are ranging from $.28 * *$ to $.92 * *$. As clear from results of the table 2 that all values carry high significant positive correlation with $\mathrm{p} \leq .001$. The results supported hypothesis $\mathrm{H} 1$ of study. A high significant strong positive correlation exists between EI and organizational culture ie .80 with $\mathrm{p}<0.001$. The determined alpha reliability of emotional intelligence is .86 and its subscale reliabilities are good enough. The determined alpha reliability of organizational culture is .94. The subscale reliabilities of organizational culture have proven enough satisfactory.

Table 2: Mean, Alpha Coefficient, Standard Deviation \& Correlation Coefficient

\begin{tabular}{|c|c|c|c|c|c|c|c|c|c|c|c|c|c|c|c|c|}
\hline Variables & $\mathbf{A}$ & $\mathbf{M}$ & SD & I & II & III & IV & $\mathbf{V}$ & VI & VII & VIII & IX & $\mathbf{X}$ & XI & XII & XIII \\
\hline 1-ER & .76 & 17.80 & 4.08 & - & & & & & & & & & & & & \\
\hline 2-ESA & .46 & 12.55 & 3.22 & $.41^{* * *}$ & - & & & & & & & & & & & \\
\hline 3-ESM & .42 & 15.70 & 3.44 & $.37^{* * *}$ & $.52^{* * *}$ & & & & & & & & & & & \\
\hline 4-EE & .51 & 16.20 & 3.46 & $.28^{* * *}$ & $.43^{* * *}$ & $.69^{* * *}$ & & & & & & & & & & \\
\hline 5-ESC & .34 & 12.73 & 2.98 & $.36^{* * *}$ & $.55^{* * *}$ & $.38^{* * *}$ & $.36^{* * *}$ & - & & & & & & & & \\
\hline 6-EAO & .32 & 12.81 & 2.77 & $.49^{* * *}$ & $.48^{* * *}$ & $.54^{* * *}$ & $.48^{* * *}$ & $.53^{* * *}$ & - & & & & & & & \\
\hline 7-EMO & .36 & 12.65 & 2.99 & $.36^{* * *}$ & $.41^{* * *}$ & $.55^{* * *}$ & $.56^{* * *}$ & $.35^{* * *}$ & $.45^{* * *}$ & - & & & & & & \\
\hline 8-Total EI & .86 & 100.4 & 16.77 & $.67^{* * *}$ & $.74^{* * *}$ & $.79^{* * *}$ & $.74^{* * *}$ & $.67^{* * *}$ & $.76^{* * *}$ & $.71^{* * *}$ & - & & & & & \\
\hline 9-INVO & .86 & 53.73 & 9.65 & $.62^{* * *}$ & $.45^{* * *}$ & $.50^{* * *}$ & $.39^{* * *}$ & $.44^{* * *}$ & $.49^{* * *}$ & $.47^{* * *}$ & $.66^{* * *}$ & - & & & & \\
\hline 10-CONS & .78 & 51.60 & 8.98 & $.54^{* * *}$ & $.54^{* * *}$ & $.53^{* * *}$ & $.48^{* * *}$ & $.57^{* * *}$ & $.52^{* * *}$ & $.46^{* * *}$ & $.71^{* * *}$ & $.81^{* * *}$ & - & & & \\
\hline 11-ADAP & .85 & 52.69 & 10.39 & $.74^{* * *}$ & $.44^{* * *}$ & $.42^{* * *}$ & $.41^{* * * *}$ & $.50^{* * * *}$ & $.52^{* * *}$ & $.44^{* * *}$ & $.69^{* * *}$ & $.72^{* * *}$ & $.77^{* * *}$ & - & & \\
\hline 12-MIS & .82 & 52.24 & 8.74 & $.58^{* * *}$ & $.58^{* * *}$ & $.58^{* * *}$ & $.54^{* * *}$ & $.53^{* * *}$ & $.58^{* * *}$ & $.45^{* * *}$ & $.76^{* * *}$ & $.69^{* * *}$ & $.70^{* * * *}$ & $.64^{* * *}$ & - & \\
\hline $\begin{array}{l}\text { 13-Total } \\
\text { OC }\end{array}$ & .94 & 210 & 33.67 & $.70^{* * *}$ & $.56^{* * *}$ & $.58^{* * *}$ & $.52^{* * * *}$ & $.57^{* * *}$ & $.59^{* * *}$ & $.51^{* * *}$ & $.80^{* * *}$ & $.90^{* * *}$ & $.92^{* * *}$ & $.88^{* * *}$ & $.85^{* * *}$ & - \\
\hline
\end{tabular}

$\mathrm{P}<.001^{* * *}$ Note: ER: emotional reasoning, ESA: Emotional Self-Awareness, ESM: emotional selfmanagement, EE: emotional expression, ESC: emotional self-control, EAO: emotional awareness of others, EM: emotional management of others, EI: emotional intelligence, INVO: Involvement, CONS: Consistency, ADAP: Adaptability, MIS: Mission, Organizational Culture: OC

H2: Organizational culture will positively predict emotional intelligence. The linear regression was computed between organizational culture and EI. The table 3 shows the regression analysis, indicating that the hypothesis was supported. The results showed that organizational culture is a significant predictor of emotional intelligence. The predictor variable organizational culture $(\beta=.801)$ has a very high significant positive effect on outcome variable with level of significant $p<.001$. The adjusted $R^{2}$ of .638 indicated organizational culture is a strong positive significant predictor that causes high significant variation; $63.8 \%$ in emotional intelligence among industrial employees. 
Table 3: Linear Regression Coefficient of Organizational Culture on Emotional Intelligence

\begin{tabular}{lcccccc|}
\hline & $\mathbf{B}$ & $\mathbf{S E}$ & $\boldsymbol{\beta}$ & $\mathbf{t}$ & $\mathbf{p}$ & $\begin{array}{c}\text { 95\% C I } \\
{[\mathbf{L L}-\mathbf{U L}]}\end{array}$ \\
\hline Constant & 16.32 & 6.46 & & 2.52 & $.01^{* *}$ & {$[3.50--29.14]$} \\
$\begin{array}{l}\text { Organizational } \\
\text { Culture }\end{array}$ & .40 & .030 & .80 & 13.19 & $.000^{* * *}$ & {$[.34--.46]$} \\
$\mathrm{R}=.801, \mathrm{R}^{2}=.642$, Adjusted $\mathrm{R}^{2}=.638$, & $\mathrm{p}<.001$ & & &
\end{tabular}

Multiple regression analysis was computed for cultural traits for Involvement, Consistency, Adaptability and Mission as predictor variable and Emotional Intelligence as outcome variable. The results in table 4 show that adjusted $\mathrm{R}^{2}$ value of .655 indicate that $65.5 \%$ variance in dependent variable can be explained by the predictors with $\mathrm{F}(4,94)=47.4$ and $\mathrm{p}<.001$. The finding show that Involvement $(\beta=.04, \mathrm{p}=.68)$ and Consistency $(\beta=.21, \mathrm{p}<.06)$ are non-significant predictors as compared to Adaptability $(\beta=.21, \mathrm{p}=.03)$ and Mission $(\beta=.43, \mathrm{p}<.01)$ that predict Emotional Intelligence significantly. The hypothesis H3: Organizational culture traits (Involvement, Consistency, Adaptability and Mission) will predict emotional intelligence positively, is supported.

Table 4: Regression Coefficients of Involvement, Consistency, Adaptability, Mission on Emotional

\begin{tabular}{|c|c|c|c|c|c|c|}
\hline Variables & B & SE & $\beta$ & $t$ & $\mathbf{p}$ & $\begin{array}{c}95 \% \mathrm{C} \mathrm{I} \\
{[\mathrm{LL}-\mathrm{UP}]}\end{array}$ \\
\hline (Constant) & 13.42 & 6.45 & & 2.07 & $.04 * *$ & [.60--26.24] \\
\hline Involvement & .07 & .19 & .04 & .40 & .68 & [-.30-- .45] \\
\hline Consistency & .40 & .22 & .21 & 1.84 & .06 & {$[-.03--.84]$} \\
\hline Adaptability & .34 & .15 & .21 & 2.17 & $.03 * *$ & [.03-- .66] \\
\hline Mission & .83 & .17 & .43 & 4.85 & $.00 * * *$ & [.49--1.17] \\
\hline
\end{tabular}

$\triangle \mathrm{R}^{2}=0.655,(\mathrm{~N}=100, \mathrm{p}<.001)$. Confidence Interval for $\mathrm{B}$

For assessing the gender differences, t-test was performed. Significant gender differences exist in organizational culture and EI. Table 5 shows that organizational culture and EI mean values are significantly higher in males as compared to female with $\mathrm{p}=.05$. Male employees have scored higher than female employees on organizational culture and emotional intelligence. Cohen 's d Value shows that effect size and the difference of the mean values is large and significant.

Table 5: Mean, Standard Deviation and t-test for Gender Differences on Organizational Culture and Emotional Intelligence

\begin{tabular}{|ccccccccc|}
\hline Variables & \multicolumn{2}{c}{ Male $(\mathbf{N}=\mathbf{8 7})$} & \multicolumn{2}{c}{ Female $(\mathbf{N = 1 3})$} & & \multicolumn{2}{c|}{ Cohen's } \\
\cline { 2 - 5 } & $\mathbf{M}$ & $\mathbf{S D}$ & $\mathbf{M}$ & $\mathbf{S D}$ & $\mathbf{t}$ & $\mathbf{p}$ & d Value \\
\hline $\begin{array}{c}\text { Organizational } \\
\begin{array}{c}\text { Culture } \\
\text { Emotional }\end{array}\end{array}$ & 212.39 & 33.39 & 192.67 & 31.77 & & 1.92 & $.057^{*}$ & 0.6 \\
Intelligence & 101.76 & 17.23 & 91.62 & 9.74 & 2.06 & $.041^{*}$ & 0.72 \\
\hline
\end{tabular}
$\mathrm{df}=98$

To study the group differences between management levels on organizational culture and emotional intelligence One-way ANOVA was carried out. It compared the management level groups by comparing their mean values on organizational culture and emotional intelligence. The results in the table 6 show that the employees scores have significant differences on organizational culture $\mathrm{F}(3,96)=2.62, \mathrm{p}=0.05 *$ and emotional intelligence $\mathrm{F}(3,96)=3.01, \mathrm{p}<.01 * *$ by management levels. Middle management has scored 
high on both variables. The differences are significant between group at upper, middle, lower and other management levels at organizational culture and emotional intelligence. The $\eta^{2}$ for organizational culture $=$ .077 and for emotional intelligence $=.086$ revealed that the effect size between group means is of moderate effect. The differences are significant and moderate.

Table 6: Mean, Standard Deviation and One Way Analysis of Variance (ANOVA) in Organizational Culture and Emotional Intelligence

\begin{tabular}{|c|c|c|c|c|c|c|c|c|c|c|}
\hline \multirow[t]{2}{*}{ Variables } & \multicolumn{2}{|c|}{$\begin{array}{c}\text { Lower } \\
\text { Management }\end{array}$} & \multicolumn{2}{|c|}{$\begin{array}{c}\text { Middle } \\
\text { Management }\end{array}$} & \multicolumn{2}{|c|}{$\begin{array}{c}\text { Senior } \\
\text { Management }\end{array}$} & \multicolumn{2}{|c|}{ Other } & \multirow[t]{2}{*}{$\begin{array}{c}F \\
(3,96)\end{array}$} & \multirow[t]{2}{*}{$\eta^{2}$} \\
\hline & $\mathbf{M}$ & SD & $\mathbf{M}$ & SD & $\mathbf{M}$ & SD & $\mathbf{M}$ & SD & & \\
\hline $\begin{array}{c}\text { Organizational } \\
\text { Culture }\end{array}$ & 213.12 & 24.96 & 214.74 & 36.54 & 202.45 & 45.47 & 181.25 & 29.79 & $2.62 *$ & .077 \\
\hline $\begin{array}{c}\text { Emotional } \\
\text { Intelligence }\end{array}$ & 99.64 & 13.04 & 105.13 & 18.41 & 96.18 & 22.48 & 87.63 & 8.73 & $3.01 *$ & .086 \\
\hline
\end{tabular}

Similarly the differences between organizations were assessed using One-way ANOVA. The Organizations (Qarshi, Pak Rison, Genome Pharmaceutical, WNS Field Pharma) were assessed by comparing their mean scores on organizational culture and EI. The results in the table show that the employees have significant differences on organizational culture $\mathrm{F}(3,96)=3.30, \mathrm{p}<0.05^{*}$ and emotional intelligence $\mathrm{F}(3,96)=2.75$, $\mathrm{p}<.05^{*}$. Qarshi has scored high mean value on organizational culture and Pak Rison has highest mean value in emotional intelligence. The differences between these organizations are significant for organizational culture and EI. The $\eta^{2}$ for organizational culture $=.095$ and for EI $=.079$ revealed that the effect size between group means is of above medium effect and significant.

Table 7: Mean, Standard deviation and One Way Analysis of Variance (ANOVA) of Organizational Culture and Emotional Intelligence

\begin{tabular}{|c|c|c|c|c|c|c|c|c|c|c|}
\hline \multirow[t]{2}{*}{ Variables } & \multicolumn{2}{|c|}{ Qarshi } & \multicolumn{2}{|c|}{ Pak Rison } & \multicolumn{2}{|c|}{$\begin{array}{c}\text { Genome } \\
\text { Pharmaceutical } \\
\end{array}$} & \multicolumn{2}{|c|}{$\begin{array}{c}\text { WNS Field } \\
\text { Pharma } \\
\end{array}$} & \multirow[t]{2}{*}{$\begin{array}{c}\text { F } \\
(3,96)\end{array}$} & \multirow[t]{2}{*}{$\eta^{2}$} \\
\hline & $\mathbf{M}$ & SD & $\mathbf{M}$ & SD & $\mathbf{M}$ & SD & $\mathbf{M}$ & SD & & \\
\hline $\begin{array}{c}\text { Organizational } \\
\text { Culture }\end{array}$ & 208.74 & 44.90 & 215.83 & 15.08 & 168.00 & 28.80 & 207.50 & 95.25 & $3.30^{*}$ & .095 \\
\hline $\begin{array}{l}\text { Emotional } \\
\text { Intelligence }\end{array}$ & 104.21 & 22.89 & 99.25 & 8.16 & 83.60 & 6.58 & 26.53 & 10.17 & $2.75^{*}$ & .079 \\
\hline
\end{tabular}

$* p<0.05$

For studying the impact of demographic characteristics on organizational culture and emotional intelligence, multiple regressions were computed. The demographic characteristics of sample included Gender, Age, Education, Management Levels, and Total Job Experience. The results in table 8 and table 9 revealed that among the demographic characteristics only Gender has a significant impact on organizational culture and EI. The adjusted $\mathrm{R}^{2}$ value of .04 indicated that $4 \%$ variance in organizational culture is accounted by the demographic characteristics with $F(5,94)=2.0$ and $p<.05$. The finding indicate that only Gender $(\beta=.02, \mathrm{p}=.04)$ predict organizational culture significantly (table 8$)$. Similarly, adjusted $\mathrm{R}^{2}$ value of .03 indicated that $3 \%$ variance in emotional intelligence is accounted by the demographic characteristics with $\mathrm{F}(5,94)=1.76$ and $\mathrm{p}<.05$. Table 9 shows only Gender $(\beta=.02, \mathrm{p}=.04)$ predict emotional intelligence significantly. The hypothesis H4, "The demographic characteristics will significantly impact the organizational culture and emotional intelligence of employees" was not supported except for Gender. The employee either male or female can impact the extent to which emotional management is done better and what traits of organizational culture have been adopted strongly. 
Table 8: Regression Coefficients of Demographic Characteristics on Organizational Culture

\begin{tabular}{|c|c|c|c|c|c|c|c|}
\hline Variables & B & SE & $\boldsymbol{\beta}$ & $\mathbf{t}$ & $\mathbf{p}$ & \multicolumn{2}{|c|}{$\begin{array}{c}95 \% \mathrm{C} \mathrm{I} \\
{[\mathrm{LL}-\mathrm{UP}]}\end{array}$} \\
\hline (Constant) & 236.49 & 16.61 & & 14.23 & .00 & {$[203.51$} & 269.48 \\
\hline Gender & -20.56 & 10.22 & -.20 & -2.01 & $.04 *$ & {$[-40.88$} & $-.25]$ \\
\hline Age & .80 & 6.42 & .01 & .12 & .90 & {$[-11.94$} & 13.56] \\
\hline Education & 4.21 & 2.67 & .16 & 1.57 & .11 & {$[-1.10$} & $9.53]$ \\
\hline $\begin{array}{l}\text { Total jobs } \\
\text { Experiance }\end{array}$ & -.91 & .62 & -.15 & -1.47 & .14 & {$[-2.15$} & $.32]$ \\
\hline Average Salary & -6.00 & 4.65 & -.13 & -1.29 & .19 & {$[-15.24$} & $3.22]$ \\
\hline
\end{tabular}

$\triangle \mathrm{R}^{2}=0.049,(\mathrm{~N}=100, \mathrm{p}<.05)$. Confidence Interval for B

Table 9: Regression Coefficients of Demographic Characteristics on Emotional Intelligence

\begin{tabular}{|cccccccc|}
\hline Variables & $\mathbf{B}$ & $\mathbf{S E}$ & $\boldsymbol{\beta}$ & $\mathbf{t}$ & $\mathbf{p}$ & \multicolumn{2}{c|}{$\begin{array}{c}\text { 95\% C I } \\
{[\mathbf{L L}-\mathbf{U P}]}\end{array}$} \\
\hline (Constant) & 114.10 & 8.27 & & 13.79 & .000 & {$[97.68$} & $-130.53]$ \\
Gender & -10.24 & 4.97 & -.20 & -2.06 & $.04 *$ & {$[-20.11$} & $-.37]$ \\
Age & 1.45 & 3.21 & .05 & .45 & .65 & {$[-4.92$} & $7.83]$ \\
Education & .74 & 1.33 & .05 & .55 & .57 & {$[-1.90$} & $3.39]$ \\
Total jobs & -.58 & .31 & -.20 & -1.86 & .06 & {$[-1.20$} & $.037]$ \\
Experiance & & & & & & & $2.87]$ \\
Average Salary & -1.74 & 2.32 & -.08 & -.749 & .456 & {$[-6.35$} & 2.87 \\
\hline
\end{tabular}

$\triangle \mathrm{R}^{2}=0.037,(\mathrm{~N}=100, \mathrm{p}<.05)$. Confidence Interval for B

\section{Discussion}

The results of this study, are important in determining the relationship between organizational culture and EI. The results have confirmed that organizational culture has a very positive highly significant correlation with EI and predict EI significantly. The previous researches also show the similar results (Danaeefard et al., 2012; Lee \& Yazdanifard, 2013; Haghighy, Shahrakimojahed \& Vahed, 2016). The traits of organizational culture: involvement, consistency, adaptability and mission possess a strong positive correlation with EI. However the adaptability and mission traits are strong and significant predictors of EI than involvement and consistency. Because adaptability and mission are associated significantly with EI than consistency and involvement. Too much involvement and consistency, in their own meaning can lower down EI. The use of refined models for measuring organizational culture by DOCS and emotional intelligence by Genos has brought novelty to existing literature. Also the industrial employees are a rarely studied sample. Demographic characteristics have also been analyzed as predictors. Previous researches have also taken demographic characteristics as predictors and found different results (Simmons, 2005). The results of this research indicated that there was no relationship between demographic characteristics of employees and organizational culture and EI. Except gender is a significant factor in predicting the direction of EI and strength of OC. And gender differences in organizational culture are significant. This is the same finding as the results of current research and other researches (Haas, \& Hwang, 2007). In case of EI, unlikely the past researches (Tagoe, \& Quarshie, 2017; Bhatti, 2013), the current research has found significant gender differences. This finding is also an addition to the literature and sample included industrial employees of Pakistan. The results of the current study have proven significant differences between employees at different management levels in organizational culture as previously confirmed by Meiring (2016). Also results of emotional intelligence have shown a significant difference between the management levels. The middle management level has scored high on both variables. It is because middle management is in interaction in between upper and lower management level. So these employees have scored high. Igbinovia and Popoola, (2016) have found higher level of EI and organizational culture among 
librarian personnel impact organizational performance but the current study has linked management level and their differences to organizational culture and EI. The current research has also studied organizational culture and EI as per case of organizational differences, thereby adding to novelty. The organization Qarshi, Pak Rison, Genome Pharmaceutical and WNS Field Pharmaceutical share the nature of business. The extraneous variables were hard to control. So the behavior of organizations can also be attributed to a lot of factors. Despite of their same geographical location, the organizations have shown differences in organizational culture. The significant differences in EI of the organizations are because of the behavioral differences and norms differences. It seems that different behaviors have been endorsed and valued. The differences of emotional intelligence are due to the different organizational culture within the organization. ie. Organizational culture predicts emotional intelligence. Different organizational culture has produced differences in emotional intelligence. Definitely different organizational cultures lead to different behavior and attitudes at work.

\section{Conclusion and Recommendations}

There are practical implications of study findings for organizations, officials and managers to further develop work attitudes and work behaviors and enhance their performance and productivity. As organizational culture is the influential predictor of EI. Both of these variables impact organizational processes and organizational outcomes. Interventions should be aimed at creating higher levels of emotional intelligence through organizational culture. Such interventions should embed and flourish certain norms, behaviors, attitude in organizational culture that concentrate on enhancing interpersonal skills of emotional regulations and emotional management. Furthermore, such norms, behaviors and attitudes should be valued, praised and rewarded to enhance emotional intelligence. Social groups, mentoring programs, appreciating bonuses, and benefit packages can be effective as reinforcement and reward for enhancing company s culture (Paraprofessional Healthcare Institute, 2001). The prominent methodological limitation of this study is the research design and sample selection. Because of the cross-sectional study and survey research method, the relationship between emotional intelligence and organizational culture was explained as relational rather than causal relation. Further studies should also research the affects of other organizational factors on EI through longitudinal study. There is a need of research to study mechanism and range of organizational variables through which organizational factors and processes influence employee behaviors and emotions. The participant selection in the study was biased and may not be representative of all employees. The major problem was that the population in Pakistan is not familiar with the importance of research and procedure. They do not realize the importance of serious participation. Longitudinal studies should be carried to examine impact of predictors. The extraneous variables need to be controlled through better sampling and research method while studying the industrial employees.

\section{References}

Aboyade, W.A. (2013). Influence of job motivation, emotional intelligence and self-concept on job performance among library workers in federal universities in Nigeria (unpublished Ph.D. thesis). University of Ibadan

Afolabi, O. A., Awosola, R. K., \& Omole, S.O. (2010). Influence of emotional intelligence and gender on job performance and job satisfaction among Nigerian policemen. Current Research Journal of Social Sciences, 2(3), 147-154.

Ahmed, M., \& Shafiq, S. (2014). The impact of organizational culture on organizational performance: A case study of telecom sector. Global Journal of Management \& Business Research, 14(3), 21-30.

Awadh, A.M., \& Saad, A.M. (2013). Impact of organizational culture on employee performance. International Review of Management and Business Research, 2(1), 168-175

Azhar, K (2003), Business Policy and Strategic Management, NewDelhi, Tata McGraw-Hill.

Bar-On, R (1996). The Emotional Quotient Inventory (EQ-I): A test of emotional intelligence. Toronto: Multi-Health Systems. 
Bar-On, R. (2004). Bar-On emotional quotient inventory: A measure of emotional intelligence technical manual. North Tonawanda, New York: Multi-Health Systems.

Bhatti, A. G. (2013). An Analysis of the general and gender difference regarding emotional intelligence among employees: Evidence from government and non-government Organizations of Hyderabad. KASBIT Business Journals (KBJ), 6, 106-113.

Brown, A. D. (1998). Organizational culture (2nd ed). London: Financial Times Management.

Brown, A. D., and Starkey, K. (2000). "Organizational identity and learning: A psychodynamic perspective." Academy of Management Review 25, no. 1, , pp. 102-120.

Browning, H., Torain, D.J. \& Patterson, T.E. (2011). Collaborative healthcare leadership: A six-part model for adapting and thriving during a time of transformative change. Center for Creative Leadership White Papers.

Danaeefard, H., Salehi, A., Hasiri, A., \& Noruzi, M.R. (2012). How emotional intelligence and organizational culture contribute to shaping learning organization in public service organization. African Journal of Business Management, 6(5), 1921-1931.

Dawson, C.S. (2010). Leading Culture Change: What Every CEO Needs to Know. Stanford: Stanford University press.

Denison, D. R. (2000). Organizational culture: Can it be a key lever for driving organizational change. In S. Cartwright, \& C. Cooper (Eds.), the handbook of organizational culture (pp. 347-372). John Wiley \& Sons, London.

Denison, D. R., \& Mishra, A. K. (1995). Toward a theory of organizational culture and effectiveness. Organization Science, 6(2), 204-223.

Downey, L. A., Roberts, J. \& Stough, C. (2011)Workplace Culture Emotional Intelligence and Trust in the Prediction of Workplace Outcomes. Int. Journal of Business Science \& Applied Management, Volume 6, Issue 1. Retrieved July 12, 2018 from http://www.business-andmanagement.org/library/2011/6_1--30-40-Downey,Roberts,Stough.pdf

Dugguh, S.I., \& Dennis, A. (2014). Job satisfaction theories: Traceability to employee performance in organizations. IOSR Journal of Business and Management, 16(5), 11-18.

Dwirantwi, E. A. (2012). Organizational culture and its effect on productivity: the case study of La Community Bank. A thesis submitted to the Institute of Distance Learning, Kwame Nkrumah University of Science and Technology in partial fulfilment of the requirements for the degree of Commonwealth Executive Masters of Public Administration. http://dspace.knust.edu.gh:8080/jspui/bitstream/123456789/4818/1/Dwirantwi,\%20Eri c\%20Addo.pdf

Extremera, N., Quintana-Orts, C., Mérida-López S. \& Rey Lourdes. (2018). Cyberbullying Victimization, Self-Esteem and Suicidal Ideation in Adolescence: Does Emotional Intelligence Play a Buffering $\begin{array}{lllll}\text { Role? } & \text { Frontiers in Psychology. } & \text { Vol: } & 9,22 . & \text { From }\end{array}$ https://www.frontiersin.org/article/10.3389/fpsyg.2018.00367

Fambrough, M. J., \& Kaye Hart, R. (2008). Emotions in Leadership Development: A Critique of Emotional Intelligence. Advances in Developing Human Resources, 10(5), 740758. https://doi.org/10.1177/1523422308323542

Genos (2018). Emotional Intelligence. https://www.genosinternational.com/emotionalintelligence/\#technical-manual

Ghenu , C. (2017). Creating awareness on the relationship between emotional intelligence, leadership and organizational culture. Proceedings of the 11th International Management Conference "The Role of Management in the Economic Paradigm of the XXIst Century” November 2nd-4th, 2017, Bucharest, Romania

Ghenu, C. \& Tudor, M. (2016, August). Emotional Intelligence in Organizational Culture - Case Study on ASE. Paper presented at 12th European Conference on Management Leadership and Governance, Bucharest, Romania. http://conferinta.management.ase.ro/archives/2016/PDF/4_11.pdf

Gignac, G. E. (2010). Seven-factor model of EI as measured by Genos EI: A confirmatory factor analytic investigation based on self- and rater-report data. European Journal of Psychological Assessment, 26, 
309-316. Retrieved on 12 July,2018 from https://www.genosinternational.com/emotionalintelligence/\#technical-manual

Goleman, D. (1995). Emotional Intelligence. New York: Bantam.

Guleryuz, K., Guney, S., Aydin, E.M., \& Asan, O. (2008). The mediating effect of job satisfaction between emotional intelligence and organizational commitment of nurses: a questionnaire survey", International Journal of Nursing Studies, 45(11), 1625-1635.

Haas, L., \& Hwang, C. P. (2007). Gender and organizational culture: Correlates of companies' responsiveness to fathers in Sweden. Gender \& Society, 21(1), 52-79.

Haghighy, M., Shahrakimojahed, L., \& Vahed, A. S. (2016). Relationship between Emotional Intelligence and Organizational Culture with Organizational Commitment of Fars province Red Crescent managers and employees. International Journal of Humanities and Cultural Studies (IJHCS) ISSN 23565926, 3(1), 1906-1923.

Hendrix, D. (2013). Emotional intelligence and the winds of change in academic libraries. ACRL Proceedings of the American Library Association, Indianapolis, IN, April 10-13 (pp. 173-180).

Igbinovia, Magnus \& Popoola, S.O.. (2016). Organizational Culture And Emotional Intelligence As Predictors Of Job Performance Among Library Personnel In Academic Libraries In Edo State, Nigeria. Journal of Information Science Theory and Practice. 4. 34-52. 10.1633/JISTaP.2016.4.2.3.

Ilyas, M., \& Abdullah, T. (2016). The Effect of Leadership, Organizational Culture, Emotional Intellegence, and Job Satisfaction on Performance. International Journal of Evaluation and Research in Education, 5, 158-164. https://www.semanticscholar.org/paper/The-Effect-of-Leadership\%2COrganizational-Culture\%2C-Ilyas-Abdullah/9328d8f93d429b975a31c0953aec97e690e9754e

Irefin, P., \& Mechanic, M. A. (2014). Effect of employee commitment on organizational performance in Coca Cola Nigeria Limited Maiduguri, Borno state. IOSR Journal of Humanities \& Social Science, 19(3), 33-41.

Jones, S.M. (2007). Emotional intelligence within organizations: A study of emotional intelligence and performance ranking within a biomedical company (Doctoral Dissertation, Pepperdine University).

Kerr R, Garvin J, Heaton N, Boyle E (2006) Emotional intelligence and leadership effectiveness. Leadership Organization Development J 27: 265-279.

Kotter, J. P., \& Heskett, J. L. (2011). Corporate culture and performance. New York: Free Press.

Langhorn, S.(2004). How emotional intelligence can improve management performance. International Journal of Contemporary Hospitality Management, 16 (4), 220-230

Lee, J. \& Yazdanifard, R. (2013). The Relationship between Emotional Intelligence, Transformational Leadership and Organizational Culture. from https://www.researchgate.net/publication/256296337

Mandell, B. \& Phevwani, S. (2003) Relationship between Emotional Intelligence and Transformational Leadership Style: A gender comparison. Journal of Business and Psychology. v. 17, n. 3, p. 387-404.

Manetje, O. \& Martins, N. (2009). "The relationship between organisational culture and organizational commitment." Southern African Business Review 13, no. 1, , pp. 87-111.

Matthews, G., Zeidner, M., \& Roberts, R. (2004). Emotional Intelligence: Science and Myth. Cambridge: The MIT Press.

Mayer, J. D., \& Salovey, P. (1997). What is emotional intelligence: Implications for educators. In P. Salovey \& D. Sluyter (Eds.),Emotional development, emotional literacy, and emotional intelligence (331). New York: Basic Books.

Mayer, J. D., Salovey, P. \& Caruso, D. R. (2004). Emotional intelligence: Theory, findings, and implications. Psychological Inquiry, 15(3), 197-215.

Mayer, J. D., Salovey, P. \& Caruso, D. R. (2008) Emotional intelligence: new ability or eclectic traits?. American Psychologist, 63(6), 503.

Mayer, J.D., Salovey, P. (2007). Mayer-Salovery-Caruso emotional intelligence test. Multi-Health Systems Incorporated.

Meiring, W. J. (2016). Risk culture at senior and middle management level: a telecommunications case study (Doctoral dissertation, North-West University (South Africa), Vaal Triangle Campus).

Moghadam, S. K., Jorfi, H., \& Jorfi, S. (2010) Impact of Emotional Intelligence on Performance of Employees. Postmodern Openings, (04), 63-74. 
Ng'ang'a, M. J., \& Nyongesa, W. J. (2012). The impact of organizational culture on performance of educational institutions. International Journal of Business \& Social Science, 3(8), 211-217.

Palmer, P.N., Jansen, C.A. (2004). Emotional intelligence as an important attribute of transformational Leadership. In Southern African Institute of Management Scientist Annual Conference, pp: 17-29.

Paraprofessional Healthcare Institute. (2001). Creating culture of retention: A coaching approach to paraprofessional supervision (A PHI Technical Series Publication). Bronx, NY: Author.

Piper LE (2008). The generation-Y workforce in health care: The new challenge for leadership. The Health Care Manag 27: 98-103.

Ranasinghe, P., Wathurapatha, W.S., Mathangasinghe, Y. \& Ponnamperuma G. (2017). Emotional intelligence, perceived stress and academic performance of Sri Lankan medical undergraduates. $B M C$ Med Educ 17, 41 from https://doi.org/10.1186/s12909-017-0884-5

Riggio RE, \& Reichard RJ (2008). The emotional and social intelligences of effective leadership: An emotional and social skill approach. J Manag Psychol 23: 169-185.

Rude, D.A. (2014). The emotionally intelligent organization: A practice and theory-based approach for culture and learning. Proceedings from EITRI: Emotional Intelligence Training and Research Institute, Waco, TX, Feb. 20-21.

Salajegheh, S., Chamanifard, R., Chamanifard, S., \& Nikpour, A. (2015). The relationship between quality of work life and organizational performance: The moderating role of demographic variables (A case study of foreign exchange units of Tejarat Bank, Iran). Asian Journal of Research in Business Economics and Management, 5(9), 128-141.

Schein, E. H. (1985). Organizational culture and leadership. San Francisco, CA: Jossey Bass.

Semadar, A., Robins, G., \& Ferris, G. R. (2006) Comparing the validity of multiple social effectiveness constructs in the prediction of managerial job performance. Journal of Organizational Behavior, 27(4), 443-461.

Shahzad, F., Iqbal, Z., \& Gulzar, M. (2013). Impact of organizational culture on employee performance: An empirical study of software houses in Pakistan. Journal of Business Studies Quarterly, 5(2), 56.

Shahzad, F., Luqman, R.A., Khan, A.R., \& Shabbir, L. (2012). Impact of organizational culture on organizational performance: An overview. Interdisciplinary Journal of Contemporary Research In Business, 3(9), 975-985.

Simmons, E. S. (2005). Predictors of Organizational Commitment Among Staff in Assisted Living . The Gerontologist, Vol. 45, No. 2, 196-205 https://academic.oup.com/gerontologist/articleabstract/45/2/196/815918

Suliman AM, Al-Shaikh FN (2007) Emotional intelligence at work: Links to conflict and innovation. Employee Relat 29: 208-220.

Sy T, Tram S, \& O'Hara LA (2006) Relation of employee and manager emotional intelligence to job satisfaction and performance. J Vocat Behav 68: 461-473. doi:10.1016/j.jvb.2005.10.003

Tagoe, T. \& Quarshie, E.N.-B. (2017). The relationship between emotional intelligence and job satisfaction among nurses in Accra. Nursing Open, 4: 84-89. https://doi.org/10.1002/nop2.

Taslimi, M. S. (2015). Management of organizational development (12th ed). Tehran: SAMT.

Tolmats, E., \& Reino, A. (2006). Interconnections of emotional intelligence and organizational culture: based on the example of two business sectors in Estonia. University of Tartu (Estonia) - Faculty of Economics and Business Administration, in: National and international aspects of organizational culture, 24, chapter 5, 121-146.

Ugoani, J.N.N. (2015) Emotional Intelligence and Organizational Culture Equilibrium - A Correlation Analysis. $J \quad A \quad$ Social Sci Humanities, 1:1, 36-47. Available at SSRN: https://ssrn.com/abstract $=2682000$

Wagner, John A (1995). "Studies of individualism-collectivism: Effects on cooperation in groups." Academy of Management journal 38, no. 1, , pp. 152-173.

Ziegler, M., Schmidt-Atzert, L., Buhner, M., \& Krumm, S. (2007). Fakability of different measurement methods for achievement motivation: Questionnaire, semi-projective, and objective. Psychology Science, 49(4), 291. 